\title{
Inflammation and peripheral arterial disease: The value of circulating biomarkers (Review)
}

\author{
SALVATORE SANTO SIGNORELLI ${ }^{1}$, VALERIO FIORE $^{1}$ and GRAZIA MALAPONTE ${ }^{2}$ \\ ${ }^{1}$ Department of Medical and Pediatric Sciences, Medical Angiology Unit, ${ }^{2}$ Department of Bio-medical Sciences, \\ General Pathology and Oncology Section, University of Catania, Catania, Italy
}

Received December 19, 2013; Accepted January 10, 2014

DOI: 10.3892/ijmm.2014.1657

\begin{abstract}
Peripheral arterial disease (PAD) is a manifestation of atherosclerotic vascular disease and is often associated with other comorbidities, such as hypertension, diabetes and dyslipidemia. An increasing body of evidence supports the notion that inflammation plays an important role in the development and progression of PAD. A number of studies have investigated the association of various acute phase proteins, particularly C-reactive protein (CRP), with PAD. Apart from CRP, other circulating biomarkers, such as matrix metalloproteinases (MMPs), selectins and interleukin (IL)-1, IL-2, IL-6, IL-8 and IL-10 have been considered to play a role in the development of PAD. In this review, the role of these circulating biomarkers in PAD is discussed. Current data indicate that the appropriate use of biomarkers in patients with PAD may contribute to an early diagnosis, an enhanced knowledge of the developmental process of the disease, as well as to the subsequent improvement of current therapies and to the development of new ones.
\end{abstract}

\section{Contents}
1. Introduction
2. Inflammation
3. CRP
4. Matrix metalloproteinases
5. Selectins
6. IL-1
7. IL-2
8. IL-6
9. IL-8
10. IL-10
11. Conclusion

Correspondence to: Professor Salvatore Santo Signorelli, Department of Medical and Pediatric Sciences, Medical Angiology Unit, University of Catania, Piazza Santa Maria di Gesù, I-95123 Catania, Italy

E-mail: ssignore@unict.it

Key words: matrix metalloproteinases, inflammation, artery disease

\section{Introduction}

Peripheral arterial disease (PAD), is one of the most common manifestations of atherosclerosis, affecting 27 million individuals in Europe and North America (1).

In 1858 Charcot (3) clearly defined and described this syndrome (and he used the term 'intermittent claudication') (2,3). Intermittent claudication is reproducibly elicited by walking-induced muscle ischemia and is consistently relieved by rest that allows reperfusion of the affected limb; thus, it may be considered as 'a leg effort angina.' Since the 1950s, Stammers (4) and Allen et al (5) independently observed that patients with intermittent claudication have a high risk of mortality due to cardiovascular events (CVs). Subsequent prospective studies on the clinical outcome of patients with PAD have yielded divergent findings; in fact, they rarely progress to limb loss; however, PAD is a powerful and independent predictor of CVs, both cardiac and cerebral (6-10). Similar to all atherosclerotic diseases (myocardial infarction, unstable angina, abdominal aortic dilatation and carotid artery disease), arterial hypertension, smoking, diabetes mellitus and hypercholesterolemia are widely considered as crucial risk factors for the development of PAD. Formerly, it was considered that arterial narrowing (stenosis), more or less critical in terms of haemodinamic efficiency, tended to lead to arterial thrombosis and as a consequence, to tissue ischemia. It is now known that the degree of arterial stenosis due to atheromatous plaque plays a significant role; however, other factors must also be considered in relation to their likelihood of causing thrombosis. A large number of cases of myocardial infarction are caused by stenosis of the coronary arteries with $>50 \%$ narrowing of the lumen (11); biomechanical stresses experienced by non-obstructing atheroma may be greater than those caused by stenoses, which yield a smaller residual lumen (14). Instead, the thrombus usually occurs due to a disruption of atherosclerotic plaque $(12,13)$. Different models of physical plaque disruption are known. In fact, a superficial erosion may occur, leading to the contact of platelets with pro-aggregatory collagen in the intima membrane $(15,16)$, whilst the majority of thromboses result from a rupture of the protective fibrous cap of the plaque, leading to the contact between blood and the highly thrombogenic material located in the lipidic core (e.g., tissue factor). The rupture of plaque plays a critical role in arterial thrombosis, considering the biomechanical ability 
of the plaque fibrous cap; the fibrous cap determines the stability of plaque. Thus, this critical issue must be analysed in molecular terms in order to provide effective means of determining the clinical outcome of patients with PAD and to obtain positive results which may improve prognosis and to reduce the extent of arterial damage and comorbidities in patients with PAD.

Data presented since 1815, the year in which cholesterol was discovered, although not yet correlated with atherosclerosis, have cited inflammation as the underlying cause of atherosclerosis $(17,18)$. In 1858, Virchow (19) found inflammatory cells in vascular plaques, and Osler (20) in 1908 suggested that inflammation and infection play a role in the pathogenesis of atherosclerosis. However, for almost a century, the inflammation hypothesis was ignored, whilst greater emphasis was placed on the putative role of cholesterol in atherosclerosis. Finally, at the end of the last millennium, many lines of evidence suggested alternative mechanisms to the cholesterol theory. Ross (21) branded atherosclerosis an inflammatory disease; to date, atherosclerosis is not only considered a disorder of pathological lipid deposition, but also as a dynamic and progressive pathophysiological process arising from a combination of endothelial dysfunction and inflammation interacting with standard risk factors. All these factors contribute to the initiation and progression of arterial damage, consequently causing clinical manifestations, as well as cardiovascular and atherosclerotic diseases, including PAD $(22,23)$.

This review focuses on the association between inflammation and PAD. Inflammatory markers along with other circulating biomarkers are discussed in the context of PAD.

\section{Inflammation}

Inflammation plays a role in the initiation and progression of PAD, and in coronary artery disease (CAD) (23-32). There are several candidate inflammatory markers, including traditional risk factors that play a pro-atherogenic role, at least in part, through an inflammatory mechanism. Cigarette smoking and diabetes mellitus, the strongest risk factors for the development of PAD, promote oxidative stress, which directly and indirectly enhances inflammatory pathways (33-38). Inflammation may also be a factor in arterial hypertension, which affects approximately $80 \%$ of patients with PAD (39). Indeed, angiotensin II elicits the production of reactive oxygen species and the expression of vascular cell adhesion molecule-1 from endothelial cells $(40,41)$. Angiotensin II increases the expression of pro-inflammatory cytokines, such as interleukin (IL)-6 and monocyte chemoattractant protein-1 (MCP-1) by arterial smooth muscle cells (SMCs) (41-43). Dyslipidemia can activate inflammatory functions by modifying the oxidation of low-density lipoproteins and of very low-density lipoproteins $(44,45)$. Other conditions that promote a systemic inflammatory response and may predispose the arterial vessels of the lower limbs to atherosclerosis are infections and systemic diseases, such as rheumatoid arthritis and systemic lupus erythematosus. Whatever the inflammatory trigger, a large number of cross-sectional and longitudinal studies have demonstrated a close link between inflammation and PAD (23-32). Notably, each of the inflammatory molecules investigated in these studies is not simply a marker of inflammation but plays an active role in peripheral atherogenesis (46-53). In 1998, Ridker et al (24) in a prospective, nested case control study carried out in apparently healthy men enrolled in the Physician's Health Study, found that the relative risk of developing PAD increased significantly with each increasing quartile of baseline C-reactive protein (CRP) concentration. This result was independent of body mass index, hypercholesterolemia, diabetes mellitus and a family history of premature atherosclerosis. The Edinburgh Artery Study also revealed that elevated levels of soluble intercellular adhesion molecule-1 (ICAM-1), but not of soluble vascular cell adhesion molecule-1, are independently associated with the development of PAD (32).

\section{CRP}

CRP is a marker of inflammation derived from leukocytes in response to IL-6 stimuli. Several actions are induced by this protein, such as the release of endothelial monocyte chemoattractor protein-1 (MCP-1), which in turn attracts monocytes towards the endothelial barrier. CRP also upregulates the release of the tissue factor and of other pro-inflammatory cytokines. Finally, CRP inhibits the release of nitric oxide (NO). The association between CRP and the development of PAD has been extensively investigated, as demonstrated from the findings of a large cross-sectional study that showed a direct association between higher levels of CRP with a lower ABI value (60). Moreover, the plasma levels of CRP were found to increase progressively as the ABI decreased in patients with PAD. Based on these results, it was postulated that CRP is an independent risk factor for the development of PAD and that subjects with higher levels of CRP have a two-fold increased risk of developing PAD. This inflammatory marker was also considered to predict the clinical outcome of arterial revascularization in patients with PAD, and conclusively a study suggested that a low plasma level of CRP of $50 \mathrm{mg} / \mathrm{l}$ is sufficient to predict the success of percutaneous angioplasty in patients with PAD and diabetes. Based on several findings from studies on patients with PAD, the data address the efficacy of a low grade of inflammation in ameliorating the outcome in patients with PAD, and also in reducing the risk of progression towards critical limb ischemia (54-61).

\section{Matrix metalloproteinases}

Matrix metalloproteinases (MMPs) are a family of $\mathrm{Zn}^{2+}$ dependent enzymes that catalyze the proteolysis of many connective extracellular matrix (ECM) tissue proteins, including collagen, fibronectin, gelatin, laminin and proteoglycans (62). MMPs are produced by a number of cells, including leukocytes, macrophages, astrocytes, neurons and microglia. These cells are involved in numerous physiological processes, including tissue remodelling during development and platelet aggregation. The activity of MMPs is negatively regulated by the so-called tissue inhibitors of matrix metalloproteinases (TIMPs) and the level of MMP activity is dependent on the balance between MMPs and TIMPs. Physiologically, the ECM proteins contribute to vessel wall integrity, as demonstrated by the role of MMPs in the development of arterial lesions and also in facilitating monocyte invasion (63). Studies using 
the gelatin zymography method have shown that two MMPs (MMP 242 and 943) are involved in arterial remodelling processes associated with atherogenesis. It has been further demonstrated that MMPs are synthesized directly in atheromatous plaques and are particularly found in arterial plaques more prone to rupture (64). High plasma levels of MMPs have been found in patients more prone to arterial damage, such as patients with type 2 diabetes and PAD, and the results have demonstrated an increased and chronic or latent level of inflammation in patients with PAD (65).

\section{Selectins}

Selectins, include E-selectins, L-selectins and P-selectins. L-selectins are a family of type-1 cell surface glycoproteins, and selectins are expressed on a variety of white blood cells, such as granulocytes, monocytes and lymphocytes. P-selectin is stored in platelet granules and in Webel-Palade bodies of endothelial cells. These glycoproteins are moved to the cell surface of endothelial cells and platelets when these cells are present in an activated form. E-selectin is not normally expressed, but is upregulated by the presence of inflammatory cytokines. The similar sequence of their homology suggests that they are able to bind similar sugar structures. This part of the molecules is known to be responsible for the different targeting and behavioural abilities of selectins. P-selectin is a target for secretory platelet granules, E-selectin for plasma membranes, and L-selectin for the tips of microfolds in leukocytes. The molecules play a crucial role in immune response, and thus these cells are deeply involved in ischemia, and also in determining the severe pathophysiological situation of ischemia-reperfusion. The effective role played by selectins in thrombus formation has been well documented by the interaction between P-selectin glycoprotein ligand 1 and P-selectin, and this interaction promotes the upregulation of the tissue factor. P-selectin is largely involved in platelet aggregation, which is a crucial key point for arterial thrombosis. These selectins were the focus of a study carried out on patients with PAD without or with type 2 diabetes (66). The results revealed high plasma levels of E-selectin (67), suggesting the involvement of this selectin in the activation process of endothelial cells that is known as crucial in the atherogenic process. In patients with PAD, plasma levels of all selectins were found to be higher compared with other groups and these levels increased following incubation with PAD plasma (68). This finding is significant, demonstrating the adhesion of neutrophils to fibrinogen. Conclusively, P-selectin plays a role in modulating the adhesion of neutrophils and is possibly associated with a lower wall shear stress of the arteries. Consequently, P-selectin is able to enhance the recruitment of activated white blood cells, leading to arterial injury. In patients with severe forms of PAD, such as critical limb ischemia, higher levels of E-selectin have been found. The role of selectins was demonstrated by a study on the polymorphisms of E-selectin. The polymorphisms were found to be independently and significantly associated with the development of PAD. Thus, it can be hypothesized that patients with PAD have a common pro-inflammatory genetic profile $(66,69)$.

In light of this, we have to consider the clinical and beneficial effects of anti-platelet agents (aspirin, clopidogrel as an antagonist of platelet P2Y12 ADP receptor and cilastazol as a phosphodiesterase inhibitor) on the plasma levels of P-selectin. Thus, this can be considered as another mechanism to explain the efficacy of anti-platelet treatment for patients with PAD beyond the simple inhibition of platelet aggregation (70-73). E-selectin can be also utilized as a medical target to evaluate the efficacy of physical supervised training in patients with PAD. The findings from a study (73) on PAD showed the positive effects of an eight-week period of exercise training on the plasma levels of E-selectin. The levels reduced after the training period; these results are proof of the pivotal role that physical training plays in the treatment of PAD and may aid in elucidating the underlying mechanisms.

\section{IL-1}

IL-1 is a typical pro-inflammatory cytokine and is a glycoprotein shown in two isoforms (IL-1 $\alpha$ and IL-1 $\beta$ ) both encoded by separate genes on chromosome 2 . These two glycoproteins act through sharing their receptor, IL-1R, present in a number of cell types. They act as endogenous pyrogens that are specifically synthesized by mononuclear cells. IL-1 stimulates both B and T lymphocyte proliferation and IL-2 receptor expression and the expression of neutrophil adhesion factors on the surface of endothelial cells. It also increases the proliferation of neutrophils, macrophages, lymphocytes, as well as chemotaxis activity. Furthermore, IL-1 increases collagen synthesis in fibroblasts and in epithelial cells, and increases the hepatic synthesis of acute phase proteins. Based on the listed biological activities, it seems to be easy to explain the potential pro-atherogenic role played by IL-1 (29,74-76). IL-1 is now considered a pivotal cytokine involved in vessel wall abnormalities that occur during high or low levels of inflammation and the start of atherosclerotic plaque formation. The data presented in several studies demonstrate that the increased plasma levels of IL-1 correlate with a higher risk of plaque instability (77). However, high levels of IL-1 have not been reported in structured studies focused on patients with PAD. The pro-atherogenic role of IL-1 may be attributed to the increased production of IL-6, as was found in the Edinburgh Artery Study, that showed IL-1 as an important predictive marker of progressive outcome in patients with PAD (32). The putative role of IL-1 in PAD can also be demonstrated through the anti-inflammatory activity of the receptor antagonist of IL-1 (IL-1ra). It is another member of the IL-1 super family that seems to have a paradoxical anti-inflammatory property by regulating IL-1 activity. It has been demonstrated that higher IL-1ra levels are often associated with prophlogistic situations. On the other hand, the exogenous administration of IL-1ra proved useful in many inflammatory diseases by improving clinical conditions and reducing organ damage. Similarly, IL-1ra has been shown to be upregulated in atherosclerosis and to correlate with the clinical progression of PAD (79).

\section{IL-2}

The IL-2 family consists of four members: IL-2, IL-4, IL-5 and granulocyte-monocyte colony-stimulating factor (GM-CSF). IL-2 is a glycoprotein with a molecular weight of $15,500 \mathrm{Da}$ encoded by a gene found on chromosome 4 . It is produced by 
activated Th1 cells and antigens. IL-2 is a T and B lymphocyte growth factor, and indeed a key activator of cytotoxic lymphocytes and nuclear killer (NK) cells. In turn, lymphocytes also stimulate the production of other cytokines, such as IL-4 and interferon $\gamma($ IFN- $\gamma)$. In atherosclerotic diseases, high levels of IL-2 have been detected in atheromatous plaques and also in the plasma and in the vascular tissue of patients with abdominal aortic aneurysms (80-82). Despite this evidence, the role of IL-2 in the pathogenesis and/or in the progression of various atherosclerotic diseases has not yet been determined. In light of this, the results of two studies, the Veterans Affairs (VA) Cooperative Study \#410 and the Iron $(\mathrm{Fe})$ and Atherosclerosis Study (FeAST) did not show an association between IL-2 plasma levels and the mortality risk of patients with PAD. However, a direct association was found between the ferritin plasma level and IL-6 levels $(83,84)$.

\section{IL-6}

IL-6 is a glycoprotein whose gene is located on chromosome 6 and is synthesized by several cells, including Th2 lymphocytes, B lymphocytes, macrophages, endothelial cells, fibroblasts, mast cells and some tumour cells (67). Several studies carried out in recent years have established a wide range of functions of IL-6 in many physiological and pathophysiological processes. Moreover, the pivotal role played by IL-6 in many pathological conditions is well known (85). The involvement of IL- 6 in the pathophysiology of atherosclerosis has been well studied; it was specifically considered in studies focused on the association between the inflammatory process and PAD. It is known that IL-6 plays a role in stimulating hepatic production in a wide range of inflammatory molecules, so-called acute-phase proteins, such as CRP, fibrinogen production, the release of complement factors and the production of serum amyloid A (86). IL-6 has several activities in the formation and maintenance of atherosclerotic plaque and it stimulates the production of MCP-1 and IL- 8 by endothelial cells and macrophages. It also increases the release of chemokines by intimal cells of the arterial wall and it seems to be able to increase the production of ICAM-1 by SMCs, and it promotes the homing of leukocytes into atherosclerotic plaque. Finally, IL- 6 promotes the transformation of SMCs into foam cells (32). The findings from studies on healthy individuals have shown a direct and significant association between the plasma levels of IL-6 with certain inflammatory biomarkers involved in the progression of atherosclerosis (i.e., TNF- $\alpha$ and CRP), and these markers are associated with an increased risk of mortality in patients with cardiovascular diseases. It has been shown that IL- 6 is an innovative predictor of PAD and a reliable marker in predicting disease clinical progression over a 12-year period. In fact, its role in PAD has been clearly defined and data from community studies have shown that it must be considered as a predictive and independent marker in the development of PAD (87). Furthermore, we have previously demonstrated that the IL-6 GG genotype promotes the development of PAD among individuals with type 2 diabetes by inducing the increased release of IL- 6 . Higher concentrations of IL-6 among those patients with the GG genotype is associated with increased plasma concentrations of fibrinogen and CRP (88).

\section{IL-8}

IL-8 was originally known as neutrophil activating protein-1 (NAP-1) and is a small protein consisting of only 79 amino acids. It is mainly produced by monocytes, macrophages and endothelial cells in response to various inflammatory stimuli. It acts by a specific receptor found only on neutrophils and it also induces the expression of $\beta-2$ integrins on neutrophil surfaces. This last activity plays a fundamental role in trans-endothelial migration (78). It has been widely demonstrated that IL-8 is closely related to the progression of atherosclerotic lesions and in fact, high levels of IL- 8 have been found in atherosclerotic plaques, rich in macrophages. In particular, IL- 8 has been found in patients with abdominal aortic aneurysms and carotid artery disease (67). In addition, mice negative for the IL-8 receptor (-/-) have shown limited atherosclerotic plaques $(79,80)$. IL- 8 is also able indeed to reduce the stability of atherosclerotic plaque by leading to an increased activity of MMPs through the blockade of TIMP-1 (81). To date, there are conflicting data on the role played by IL-8 in patients with PAD. However, the results from a study performed on patients with PAD that were submitted to vascular surgical procedure revealed a higher production of IL-8 in polymorphonuclear leukocytes [Marino et al (89)]. The plasma levels of IL 8 were lower in patients with PAD compared to healthy individuals and to subjects with cardiovascular risk, both under resting consitions and following stimulated production.

\section{IL-10}

IL-10 is a pure protein and is mainly produced by Th2 lymphocytes, and, to a lesser extent, by monocytes, macrophages and activated $\mathrm{T}$ lymphocytes. It inhibits the production of cytokines by Th1 lymphocytes (IFN- $\gamma$, TNF- $\alpha$, IL-2 and IL-3) and it also inhibits the production of interleukins derived from macrophages (IL-1, IL-6, IL-8, GM-CSF, TNF- $\alpha$ ). IL-10 gene transfer can significantly reduce the atherosclerotic plaque area and the macrophage infiltrated area (90). Other relevant proof of the anti-inflammatory and immunosuppressive activity of IL-10 has been demonstrated by Mallat et al. They showed that the lack of the IL-10 (IL-10-deficient C57BL/6J mice) determines a significant 3-fold increase in lipid accumulation in atherosclerotic plaque compared with wild-type mice, and also showed an increased T-cell infiltration and an abundant IFN- $\gamma$ expression, and decreased collagen content in the atherosclerotic lesions of deficient mice (91). In advanced atherosclerotic plaques, IL-10 was found and this finding was associated with the reduced apoptosis of cells of the lipid core and thereby in the reduced risk of the plaque rupture (92). To date, few studies have focused on the role of IL-10 in PAD. In particular, it is difficult to demonstrate the correlation between the levels of IL-10 with the progression of atherosclerotic lesions and clinical outcome. In fact, it is still unclear whether high plasma levels of IL-10 are to be considered as a marker of anti-inflammatory patterns (with a reduced likelihood of developing atherosclerosis), or conversely whether they are as counter regulatory consequences related to primitive pro-inflammatory patterns. Data from studies on CAD have linked the high plasma levels of IL-10 with a lower pro-inflammatory profile and with a better prognosis in 
patients with acute coronary syndrome $(93,94)$. By contrast, few studies suggest a correlation between PAD and reduced plasma levels of IL-10 and this emphasizes the uncertain role played by this cytokine in the pathogenesis of atherosclerotic processes. Of note, such polymorphisms of the IL-10 gene are related to altered transcriptional activity and protein levels. A study performed by Blanco et al (95) showed that the IL-10 proximal promoter haplotype IL-10G*11/-1082G/-819C/-592C is more frequent in patients with aortic severe occlusive disease than in the control subjects. In addition, it was found that the IL-10 ATA haplotype seemed to correlate with a short-term risk of acute post-operative cardiovascular events and in PAD patients with reduced endothelial function (96).

\section{Conclusion}

It is clear from this review that recent progress in the physiopathology of PAD have implicated inflammation as a key contributor to the initiation of vascular damage. Circulating biomarkers, apart from CRP, such as MMPs, selectins, IL-1, IL-2, IL-6, IL-8 and IL-10, are useful for the clinical characterization of PAD. In fact, an increasing body of evidence supports the notion that several circulating biomarkers are associated with the main aspects of PAD. The demonstration that cytokines and MMPs play a pathogenic role in PAD may encourage the development of novel therapeutic approaches for the prevention and management of PAD. However, additional studies on this matter are required to develop clinically useful markers of PAD by using novel approaches, such as proteomics.

\section{References}

1. Norgern L, Hiatt WR, Dormandy JA, Nehler MR, Harris KA and Fowkes FG; TASC II Working Group: Inter-society consensus for management of peripheral arterial diseases (TASCII). J Vasc Surg 45 (Suppl S): S5-S67, 2007.

2. Brodie BC: Lectures illustrative of various subjects in pathology and surgery. London, A Spottiswoode, 1846.

3. Charcot JMC: Sur la claudication intermittente observe dans un cas d'obliteration complete de l' une des arteres iliaques primitives. CR Soc Biol (Paris) 5: 225, 1858.

4. Stammers FA: Peripheral arterial disease; some points of common interest to general and orthopaedic surgery. J Bone Joint Surg Br 36-B: 209-217, 1954.

5. Allen EV, Barker NW and Hines EA: Peripheral Vascular Diseases. 1st edition. W.B. Saunders, Co., Philadelphia, PA, pp343-401, 1946.

6. O'Riordain DS and O'Donnell JA: Realistic expectations for the patient with intermittent claudication. Br J Surg 78: 861-863, 1991.

7. Criqui MH, Langer RD, Fronek A, Feigelson HS, Klauber MR, McCann TJ and Browner D: Mortality over a period of 10 years in patients with peripheral arterial disease. N Engl J Med 326 : 381-386, 1992.

8. Leng GC, Lee AJ, Fowkes FG, Whiteman M, Dunbar J, Housley E and Ruckley CV: Incidence, natural history and cardiovascular events in symptomatic and asymptomatic peripheral arterial disease in the general population. Int J Epidemiol 25: 1172-1181, 1996.

9. Brevetti G, Martone VD, Perna S, Cacciatore F, Corrado S, Di Donato A and Di Iorio A: Intermittent claudication and risk of cardiovascular events. Angiology 49: 843-848, 1998.

10. Brevetti G, Schiano V, Verdoliva S, Silvestro A, Sirico G, De Maio J, Lanero S and Chiariello M: Peripheral arterial disease and cardiovascular risk in Italy. Results of the Peripheral Arteriopathy and Cardiovascular Events (PACE) study. J Cardiovasc Med (Hagerstown) 7: 608-613, 2006.
11. Ridker PM: Are associations between infection and coronary disease causal or due to confounding? Am J Med 106: 376-377, 1999.

12. Mendez MV, Scott T, LaMorte W, Vokonas P, Menzoian JO and Garcia R: An association between periodontal disease and peripheral vascular disease. Am J Surg 176: 153-157, 1998.

13. Hung HC, Willett W, Merchant A, Rosner BA, Ascherio A and Joshipura KJ: Oral health and peripheral arterial disease. Circulation 107: 1152-1157, 2003.

14. Wiesli P and Schulthess G: Effect of roxithromycin treatment on the endothelial function of Chlamydia pneumoniae seropositive men suffering from peripheral arterial occlusive disease. Circulation 106: e226, 2002.

15. Wiesli P, Czerwenka W, Meniconi A, Maly FE, Hoffmann U, Vetter W and Schulthess G: Roxithromycin treatment prevents progression of peripheral arterial occlusive disease in Chlamydia pneumoniae seropositive men: a randomized, double-blind, placebo-controlled trial. Circulation 105: 2646-2652, 2002.

16. Krayenbuehl PA, Wiesli P, Maly FE, Vetter W and Schulthess G: Progression of peripheral arterial occlusive disease is associated with Chlamydia pneumoniae seropositivity and can be inhibited by antibiotic treatment. Atherosclerosis 179: 103-110, 2005.

17. Vance DE and Van den Bosch H: Cholesterol in the year 2000. Biochim Biophys Acta 1529: 1-8, 2000.

18. Hodgson JA: Treatise on the Diseases of Arteries and Veins. Thomas Underwood, London, UK, 1815.

19. Virchow R: Cellular Pathology. John Churchill, London, UK, 1858.

20. Osler W: Diseases of the arteries. In: Modern Medicine: Its Practice and Theory. Lea and Febiger, Philadelphia, PA, pp429-447, 1908.

21. Ross: Atherosclerosis - an inflammatory disease. N Engl J Med 340: 115-126, 1999.

22. Libby P, Ridker PM and Maseri A: Inflammation and atherosclerosis. Circulation 105: 1135-1143, 2002.

23. Brevetti G, Schiano V and Chiariello M: Endothelial dysfunction: a key to the pathophysiology and natural history of peripheral arterial disease? Atherosclerosis 197: 1-11, 2008.

24. Ridker PM, Cushman M, Stampfer MJ, Tracy RP and Hennekens $\mathrm{CH}$ : Plasma concentration of C-reactive protein and risk of developing peripheral vascular disease. Circulation 97: 425-428, 1998.

25. Bloemenkamp DG, van den Bosch MA, Mali WP, Tanis BC, Rosendaal FR, Kemmeren JM, Algra A, Visseren FL and van der Graaf Y: Novel risk factors for peripheral arterial disease in young women. Am J Med 113: 462-467, 2002.

26. Pradhan AD, Rifai N and Ridker PM: Soluble intercellular adhesion molecule-1, soluble vascular adhesion molecule-1, and the development of symptomatic peripheral arterial disease in men. Circulation 106: 820-825, 2002.

27. Brevetti G, Oliva G, Silvestro A, Scopacasa F and Chiariello M; Peripheral Arteriopathy and Cardiovascular Events (PACE) Study Group: Prevalence, risk factors and cardiovascular comorbidity of symptomatic peripheral arterial disease in Italy. Atherosclerosis 175: 131-138, 2004.

28. Wildman RP, Muntner P, Chen J, Sutton-Tyrrell K and He J: Relation of inflammation to peripheral arterial disease in the National Health and Nutrition Examination Survey, 1999-2002: Am J Cardiol 96: 1579-1583, 2005.

29. Tzoulaki I, Murray GD, Lee AJ, Rumley A, Lowe GD and Fowkes FG: C-reactive protein, interleukin-6, and soluble adhesion molecules as predictors of progressive peripheral atherosclerosis in the general population: Edinburgh Artery Study. Circulation 112: 976-983, 2005.

30. Hoogeveen RC, Morrison A, Boerwinkle E, Miles JS, Rhodes CE, Sharrett AR and Ballantyne CM: Plasma MCP-1 level and risk for peripheral arterial disease and incident coronary heart disease: Atherosclerosis Risk in Communities study. Atherosclerosis 183: 301-307, 2005.

31. Cassar K, Bachoo P, Ford I, Greaves M and Brittenden J: Markers of coagulation activation, endothelial stimulation and inflammation in patients with peripheral arterial disease. Eur J Vasc Endovasc Surg 29: 171-176, 2005.

32. Tzoulaki I, Murray GD, Lee AJ, Rumley A, Lowe GD and Fowkes FG: Inflammatory, haemostatic, and rheological markers for incident peripheral arterial disease: Edinburgh Artery Study. Eur Heart J 28: 354-362, 2007. 
33. Fowkes FG, Housley E, Riemersma RA, Macintyre CC, Cawood EH, Prescott RJ and Ruckley CV: Smoking, lipids, glucose intolerance, and blood pressure as risk factors for peripheral atherosclerosis compared with ischemic heart disease in the Edinburgh Artery Study. Am J Epidemiol 135: 331-340, 1992.

34. Murabito JM, D'Agostino RB, Silbershatz H and Wilson WF: Intermittent claudication: a risk profile from the Framingham Heart Study. Circulation 96: 44-49, 1997.

35. Pryor WA and Stone K: Oxidants in cigarette smoke: radicals, hydrogen peroxide, peroxynitrate, and peroxynitrite. Ann NY Acad Sci 686: 12-27, 1993.

36. Morrow JD, Frei B, Longmire AW, Gaziano JM, Lynch SM, Shyr Y, Strauss WE, Oates JA and Roberts LJ II: Increase in circulating products of lipid perioxidation (F2-isoprostanes) in smokers. Smoking as a cause of oxidative damage. N Engl J Med 332: 1198-1203, 1995.

37. Baynes JW and Thorpe SR: Role of oxidative stress in diabetic complications: a new perspective on an old paradigm. Diabetes 48: 1-9, 1999.

38. Rahman I and Adcock IM: Oxidative stress and redox regulation of lung inflammation in COPD. Eur Respir J 28: 219-242, 2006.

39. Hirsch AT, Criqui MH, Treat-Jacobson D, Regensteiner JG, Creager MA, Olin JW, Krook SH, Hunninghake DB, Comerota AJ, Walsh ME, McDermott MM and Hiatt WR: Peripheral arterial disease detection, awareness, and treatment in primary care. JAMA 286: 1317-1324, 2001.

40. Griendling KK, Ushio-Fukai M, Lassegue B and Alexander RW: Angiotensin II signaling in vascular smooth muscle. New concepts. Hypertension 29: 366-373, 1997.

41. Kranzhofer R, Schmidt J, Pfeiffer CA, Hagl S, Libby P and Kubler W: Angiotensin induces inflammatory activation of human vascular smooth muscle cells. Arterioscler Thromb Vasc Biol 19: 1623-1629, 1999.

42. Hernandez-Presa M, Bustos C, Ortego M, Tunon J, Renedo G, Ruiz-Ortega $\mathrm{M}$ and Egido J: Angiotensin-converting enzyme inhibition prevents arterial nuclear factor-kappa B activation, monocyte chemoattractant protein-1 expression, and macrophage infiltration in a rabbit model of early accelerated atherosclerosis. Circulation 95: 1532-1541, 1997.

43. Tummala PE, Chen XL, Sundell CL, Laursen JB, Hammes CP, Alexander RW, Harrison DG and Medford RM: Angiotensin II induces vascular cell adhesion molecule-1 expression in rat vasculature: a potential link between the renin-angiotensin system and atherosclerosis. Circulation 100: 1223-1229, 1999.

44. Cushing SD, Berliner JA, Valente AJ, Territo MC, Navab M, Parhami F, Gerrity R, Schwartz CJ and Fogelman AM: Minimally modified low density lipoprotein induces monocyte chemotactic protein 1 in human endothelial cells and smooth muscle cells. Proc Natl Acad Sci USA 87: 5134-5138, 1990.

45. Rajavashisth TB, Andalibi A, Territo MC, Berliner JA, Navab M, Fogelman AM and Lusis AJ: Induction of endothelial cell expression of granulocyte and macrophage colony-stimulating factors by modified low-density lipoproteins. Nature 344: 254-257, 1990

46. Li JJ and Fang CH: C-reactive protein is not only an inflammatory marker but also a direct cause of cardiovascular diseases. Med Hypotheses 62: 499-506, 2004.

47. Galkina $\mathrm{E}$ and Ley K: Vascular adhesion molecules in atherosclerosis. Arterioscler Thromb Vasc Biol 27: 2292-2301, 2007.

48. Tedgui A and Mallat Z: Cytokines in atherosclerosis: pathogenic and regulatory pathways. Physiol Rev 86: 515-581, 2006.

49. Braunersreuther V, Mach F and Steffens S: The specific role of chemokines in atherosclerosis. Thromb Haemost 97: 714-721, 2007.

50. Roldan V, Marin F, Lip GY and Blann AD: Soluble E-selectin in cardiovascular disease and its risk factors. A review of the literature. Thromb Haemost 90: 1007-1020, 2003.

51. Nielsen LB: Atherogenecity of lipoprotein(a) and oxidized low density lipoprotein: insight from in vivo studies of arterial wall influx, degradation and efflux. Atherosclerosis 143: 229-243, 1999.

52. Carmelli D, Fabsitz RR, Swan GE, Reed T, Miller B and Wolf PA: Contribution of genetic and environmental influences to ankle-brachial blood pressure index in the NHLBI Twin Study. National Heart, Lung, and Blood Institute. Am J Epidemiol 151: 452-458, 2000.

53. Thomas JC, Vohra RS, Beer S, Bhatti K, Ponnambalam S and Homer-Vanniasinkam S: Biomarkers in peripheral arterial disease. Trends Cardiovasc Med 19: 147-151, 2009.
54. Fiessinger JN and Schäfer M: Trial of iloprost versus aspirin treatmentfor critical limb ischaemia of thromboangiitis obliterans. The TAO Study. Lancet 335: 555-557, 1990.

55. Dormandy J: Use of the prostacyclin analogue iloprost in the treatment of patients with critical limb ischaemia. Therapie 46: 319-322, 1991.

56. Lessiani G, Vazzana N, Cuccurullo C, Di Michele D, Laurora G, Sgrò G, Di Ruscio P, Simeone E, Di Iorio P, Lattanzio S, Liani R, Ferrante E and Davì G: Inflammation, oxidative stress and platelet activation in aspirin-treated critical limb ischaemia: beneficial effects of iloprost. Thromb Haemost 105: 321-328, 2011.

57. Miyashita Y, Saito S, Miyamoto A, Iida O and Nanto S: Cilostazol increases skin perfusion pressure in severely ischemic limbs. Angiology 62: 15-17, 2011.

58. Shalhoub J, Davies AH and Franklin IJ: Cilostazol may improve outcome in critical limb ischemia. Int Angiol 28: 363-366, 2009.

59. Sigvant B, Wiberg-Hedman K, Bergqvist D, Rolandsson O, Andersson B, Persson E and Wahlberg E: A population-based study of peripheral arterial disease prevalence with special focus on critical limb ischemia and sex differences. J Vasc Surg 45: 1185-1191, 2007.

60. Folsom AR, Pankow JS, Tracy RP, Arnett DK, Peacock JM, Hong Y, Djoussé L and Eckfeldt JH; Investigators of the NHBLI Family Heart Study: Association of C-reactive protein with markers of prevalent atherosclerotic disease. Am J Cardiol 88: 112-117, 2001.

61. Galis ZS and Khatri JJ: Matrix metalloproteinases in vascular remodeling and atherogenesis: the good, the bad, and the ugly. Circ Res 90: 251-262, 2002.

62. Galis ZS, Johnson C, Godin D, Magid R, Shipley JM, Senior RM and Ivan E: Targeted disruption of the matrix metalloproteinase-9 gene impairs smooth muscle cell migration and geometrical arterial remodeling. Circ Res 91: 852-859, 2002.

63. Galis ZS, Sukhova GK, Lark MW and Libby P: Increased expression of matrix metalloproteinases and matrix degrading activity in vulnerable regions of human atherosclerotic plaques. J Clin Invest 94: 2493-2503, 1994.

64. Signorelli SS Malaponte G, Libra M, Di Pino L, Celotta G, Bevelacqua V, Petrina $M$, Nicotra GS, Indelicato $M$, Navolanic PM, Pennisi G and Mazzarino MC: Plasma levels and zymographic activities of matrix metalloproteinases 2 and 9 in type II diabetics with peripheral arterial disease. Vasc Med 10: $1-6,2005$.

65. Ley K: The role of selectins in inflammation and disease. Trends Mol Med 9: 263-268, 2003.

66. Boulbou MS, Koukoulis GN, Vasiou KG, Petinaki EA, Gourgoulianis KI and Fezoulidis IB: Increased soluble E-selectin levels in type 2 diabetic patients with peripheral arterial disease. Int Angiol 23: 18-24, 2004.

67. Signorelli SS, Mazzarino MC, Di Pino L, Malaponte G, Porto C, Pennisi G, Marchese G, Costa MP, Digrandi D, Celotta G and Virgilio V: High circulating levels of cytokines (IL-6 and TNFalpha), adhesion molecules (VCAM-1 and ICAM-1) and selectins in patients with peripheral arterial disease at rest and after a treadmill test. Vasc Med 8: 15-19, 2003.

68. Flex A, Gaetani E, Angelini F, Sabusco A, Chillà C, Straface G, Biscetti F, Pola P, Castellot JJ Jr and Pola R: Pro-inflammatory genetic profiles in subjects with peripheral arterial occlusive disease and critical limb ischemia. J Intern Med 262: 124-130, 2007.

69. Merten $\mathrm{M}$ and Thiagarajan P: P-selectin in arterial thrombosis. Z Kardiol 93: 855-863, 2004

70. Rao AK, Vaidyula VR, Bagga S, Jalagadugula G, Gaughan J, White DB and Commerota AJ: Effect of antiplateletagents clopidogrel, aspirin and cilastazol on circulating tissue factor procoagulant activity in patients with peripheral arterial disease. Thromb Haemost 96: 738-743, 2006.

71. Dinarello CA: Blocking interleukin-1 $\beta$ in acute and chronic autoinflammatory diseases. J Intern Med 269: 16-28, 2011.

72. Dinarello CA: IL-18: A TH1-inducing, proinflammatory cytokine and new member of the IL-1 family. J Allergy Clin Immunol 103: 11-24, 1999.

73. Saetre T, Enoksen E, Lyberg T, Stranden E, Jørgensen JJ, Sundhagen JO and Hisdal J: Supervised exercise training reduces plasma levels of the endothelial inflammatory markers E-selectin and ICAM-I in patients with peripheral arterial disease. Angiology 62: 301-305, 2011.

74. Libby P, Sukhova G, Lee RT and Galis ZS: Cytokines regulate vascular functions related to stability of the atherosclerotic plaque. J Cardiovasc Pharmacol 25 (Suppl 2): S9-S12, 1995. 
75. Fiotti N, Giansante C, Ponte E, Delbello C, Calabrese S, Zacchi T, Dobrina A and Guarnieri G: Atherosclerosis and inflammation. Patterns of cytokine regulation in patients with peripheral arterial disease. Atherosclerosis 145: 51-60, 1999.

76. McDermott MM, Guralnik JM, Corsi A, Albay M, Macchi C, Bandinelli $\mathrm{S}$ and Ferrucci L: Patterns of inflammation associated with peripheral arterial disease: the InCHIANTI study. Am Heart J 150: 276-281, 2005.

77. Dinarello CA: Interleukin-1. Cytokine Growth Factor Rev 8: 253-265, 1997.

78. Bresnihan B, Alvaro-Gracia JM, Cobby M, Doherty M, Domljan Z, Emery P, Nuki G, Pavelka K, Rau R, Rozman B, Watt I, Williams B, Aitchison R, McCabe D and Musikic P: Treatment of rheumatoid arthritis with recombinant human interleukin-1 receptor antagonist. Arthritis Rheum 41: 2196-2204, 1998.

79. Malek TR and Castro I: Interleukin-2 receptor signaling: at the interface between tolerance and immunity. Immunity 33 $153-165,2010$.

80. Lindholt JS and Shi GP: Chronic inflammation, immune response, and infection in abdominal aortic aneurysms. Eur J Vasc Endovasc Surg 31: 453-463, 2006.

81. Wan YY and Flavell RA: The roles for cytokines in the generation and maintenance of regulatory T cells. Immunol Rev 212: $114-130,2006$

82. Khew-Goodall Y, Wadham C, Stein BN, Gamble JR and Vadas MA: Stat6 activation is essential for interleukin-4 induction of P-selectin transcription in human umbilical vein endothelia cells. Arterioscler Thromb Vasc Biol 19: 1421-1429, 1999.

83. Depalma RG, Hayes VW, Chow BK, Shamayevu G, May PE and Zackarski LR: Ferritin levels, inflammatory biomarkers, and mortality in peripheral arterial disease: a substudy of the Iron (Fe) and Atherosclerosis Study (FeAST) Trial. J Vasc Surg 51: $1498-1503,2010$

84. Nylaende M, Kroese A, Stranden E, Morken B, Sandbaek G, Lindahl AK, Arnesen H and Seljeflot I: Markers of vascular inflammation are associated with the extent of atherosclerosis assessed as angiographic score and treadmill walking distances in patients with peripheral arterial occlusive disease. Vasc Med 11: 21-28, 2006.

85. McDermott MM, Liu K, Ferrucci L, Tian L, Guralnik JM, Tao H, Ridker PM and Criqui MH: Relation of interleukin-6 and vascular cellular adhesion molecule-1 levels to functional decline in patients with lower extremity peripheral arterial disease. Am J Cardiol 107: 1392-1398, 2011.

86. Akira S, Taga T and Kishimoto T: Interleukin-6 in biology and medicine. Adv Immunol 54: 1-78, 1993.

87. Sabat R, Grütz G, Warszawska K, Kirsch S, Witte E, Wolk K and Geginat J: Biology of interleukin-10. Cytokine Growth Factor Rev 21: 331-344, 2010.
88. Libra M, Signorelli SS, Bevelacqua Y, Navolanic PM, Bevelacqua V, Polesel J, Talamini R, Stivala F, Mazzarino MC and Malaponte G: Analysis of G(-174)C IL-6 polymorphism and plasma concentrations of inflammatory markers in patients with type 2 diabetes and peripheral arterial disease. J Clin Pathol 59: 211-215, 2006

89. Marino F, Guasti L, Tozzi M, Consuelo Maio R, Castiglioni L, Rasini E, Schembri L, Maroni L, Legnaro M, De Leo A Piffaretti G, Castelli P, Venco A, Lecchini S and Cosentino M: Angiotensin type 1 receptor expression and interleukin- 8 production in polymorphonuclear leukocytes of patients with peripheral arterial disease. J Cardiovasc Pharmacol 54: 520-525, 2009.

90. Mallat Z, Besnard S, Duriez M, Deleuze V, Emmanuel F, Bureau MF, Soubrier F, Esposito B, Duez H, Fievet C, Staels B, Duverger N, Scherman D and Tedgui A: Protective role of interleukin-10 in atherosclerosis. Circ Res 85: e17-e24, 1999.

91. Mallat Z, Heymes C, Ohan J, Faggin E, Leseche G and Tedgui A: Expression of interleukin-10 in advanced human atherosclerotic plaques: relation to inducible nitric oxide synthase expression and cell death. Arterioscler Thromb Vasc Biol 19: 611-616, 1999.

92. Tiret L, Godefroy T, Lubos E, Nicaud V, Tregouet DA, Barbaux S, Schnabel R, Bickel C, Espinola-Klein C, Poirier O, Perret C, Münzel T, Rupprecht HJ, Lackner K, Cambien F and Blankenberg S; AtheroGene Investigators: Genetic analysis of the interleukin-18 system highlights the role of the interleukin-18 gene in cardiovascular disease. Circulation 112: 643-650, 2005.

93. Anguera I, Miranda-Guardiola F, Bosch X, Filella X, Sitges M, Marín JL, Betriu A and Sanz G: Elevation of serum levels of the anti-inflammatory cytokine interleukin-10 and decreased risk of coronary events in patients with unstable angina. Am Heart J 144: 811-817, 2002.

94. Smith DA, Irving SD, Sheldon J, Cole D and Kaski JC: Serum levels of the antiinflammatory cytokine interleukin-10 are decreased in patients with unstable angina. Circulation 104: 746-749, 2001.

95. Blanco E, Moñux G, Mas A, Serrano FJ, de la Concha EG and Urcelay E: Role of IL-10 promoter polymorphisms in the development of severe aorto-iliac occlusive disease. Hum Immunol 69: 651-654, 2008

96. Heeschen C, Dimmeler S, Hamm CW, Fichtlscherer S, Boersma E, Simoons ML and Zeiher AM; CAPTURE Study Investigators: Serum level of the antiinflammatory cytokine interleukin-10 is an important prognostic determinant in patients with acute coronary syndromes. Circulation 107: 2109-2114, 2003. 